\title{
Designing of the School Uniforms for Pre-School Children
}

\author{
Lalita Rani* \\ Department of Textile and Apparel Designing, COHSC, CCSHAU, Hisar, India \\ *Corresponding author
}

\begin{tabular}{l} 
K e y w o r d s \\
Pre-school children, \\
School uniforms, \\
Self-help features, \\
Suitability \\
Article Info \\
$\begin{array}{l}\text { Accepted: } \\
\text { 20 January } 2020 \\
\text { Available Online: } \\
\text { 10 February } 2020\end{array}$ \\
\hline
\end{tabular}

A B S T R A C T

The present study focused on the pre-schoolers uniforms and designing of the uniforms with suitable features. A total of thirty school uniforms were designed under three categories. Keeping in mind the features of the pre-schoolers clothing i.e. comfort, smartness, appealing and style with self help features designing was done. Each category had ten designs. The categories were-A) Boys' summer uniform, (B) Girls' summer uniform and (C) Winter uniform for boys and girls. The following steps were followed for designing of the pre-schoolers uniforms were- evaluation of designs, sourcing of the fabrics and construction of the selected best designs. The sketches of created designs on drawing sheets were displayed on a wall in sufficient natural light, for the aesthetic evaluation of designs. A panel of ten judges included experts from the faculty of Clothing and Textiles, Human development \& Family relations, and two nursery teachers of Chaitanya Laboratory Nursery School of Govt. Home- Science College, Chandigarh. Sourcing was done for the suitable material for the summer uniform in plains, checks and stripes. These were then displayed and were selected by the panel of judges. The top three materials were then selected for the construction of summer uniform. Three top ranking school uniforms from the two categories were then constructed according to the standard measurements being used by the uniform manufacturing people. Only summer uniforms were constructed for boys and girls.

\section{Introduction}

The pre-school age is the age to introduce them to the school and a different environment. Uniforms in schools help the children to identify with their institution. School uniforms are the distinctive design clothing worn by the students of schools and are purposely designed for undifferentiated identification. The word 'uniform' means literally having the same form.' So a school uniform means that every kid in the school wears the same clothes (though girls often have a different uniform to boys). A school uniform is an outfit- a set of standardized clothes-worn primarily for an educational institution (en.wikipedia.org/wiki/schooluniform).

Taking an account of clothing requirements of pre-schoolers, their school uniform should bepatterned for growth; have ease and freedom 
yet it should not be too large; well constructed to stand hard wear and be comfortable; roomy neck opening; strong reinforcements at all points of strain such as placket-openings, pocket-corners, knees, elbows, armholes and under buttons; closely woven material which will remain fresh even after several washes; good workmanship, durable flat seams; simple, accompanied by becomingness of line and colour; fasteners sewn firmly to withstand tugging and pulling and button holes closely worked; school shoes should be comfortable with good fit and material of shoes should be durable (Gawne et al., 1969).

The ideal clothes for the Pre-school children should therefore be soft, comfortable, lightweight, non-irritating, absorbent, nonflammable and easy to put on and take off and comparatively loose. Some other features that can make their clothes more comfortable are adjustable straps on overalls and skirts. The Raglan sleeves allow for growth better then set in sleeves. Some clothes are made with tucks and pleats at the shoulder line to allow for increased width and avoid waistline seam for girl's dresses. A set-in-band across the front two or more inches in width with a sash in the back accomplishes the same-effect but allows for growth. Lines should emphasize desirable features and camouflage undesirable ones. Pockets for a hankie and a little girl's "valuables" encourage neatness and help provide a sense of self-importance. Patch pockets are easy to reach and likely to tear if placed on the slant. Self-help features for little boys as well as sturdy construction are important. If trousers or overalls are all of the same style, self-help is easier and the small one feels more secure. Variety can be obtained by colour and fabric differences (Ryan 1966).

The pre-school period is a critical one in the development of the child. Not only do physical defects manifest themselves but also faulty attitudes, anxieties, insecurities, instabilities and distortion of personality may be produced. Clothing can help to make childhood a delightful period. Parents and teacher should understand the effect of clothing on the developing personality of the child. The child at this age is learning to dress. Studies have shown that learning independence in one area fosters independence and self- confidence in other areas, so clothing that is easy to put on and take off may be beneficial beyond the particular skill of dressing (Lewis and Dora 1960). Keeping in mind the vital role of clothing in building up the self concept and personality of an individual right from his pre-school days, the study-"uniforms for preschool children" was taken up to cover an important area of clothing in child's life i.e. the uniforms which usually does not get attention much on the part of parents as well as the school authorities.

\section{Materials and Methods}

A total of thirty school uniforms were designed under three categories. Keeping in mind the features of the pre-schoolers clothing i.e. comfort, smartness, appealing and style with self help features designing was done. Each category had ten designs. The categories were-

1. Boys' summer uniform

2. Girls' summer uniform

3. Winter uniform for boys and girls

\section{Evaluation of designs}

The sketches of created designs on drawing sheets were displayed on a wall in sufficient natural light, for the aesthetic evaluation of designs. A panel of ten judges included experts from the faculty of Clothing and Textiles, Human development \& Family relations, and two nursery teachers of 
Chaitanya Laboratory Nursery School of Govt. Home- Science College, Chandigarh. These judges were asked to give the ranks in order of their preference for each design from each category on the given Performa. Marks were allotted to these preferences, ten marks to first preference and one to least preferred design. Total scores were calculated for each design by multiplying the frequency by the marks allotted.

\section{Sourcing of material}

Sourcing was done for the suitable material for the summer uniform in plains, checks and stripes. These were then displayed and were selected by the panel of judges. The top three materials were then selected for the construction of summer uniform.

\section{Construction of selected designs}

Three top ranking school uniforms from the two categories were then constructed according to the standard measurements being used by the uniform manufacturing people.

\section{Designing and construction of uniforms for pre-schoolers}

The results of the study are presented as follows:-

\section{Selection of the fabric for the uniforms}

The ranks of ten samples of different colours and checks shown to the judges for selection were as follows:-

Table 1 reveals that sample no 10 was the most preferred fabric with a score of 80 , and was ranked first. Sample no 5 got 70 marks and ranked second followed by Sample no 8 at third position with 75 marks. Sample no 1 and 4 were on the fourth and fifth positions with 65 and 60 marks respectively. Sixth to tenth ranks in descending order were bagged by $6,9,2,3$ and 6 respectively. Therefore, Sample no 10, 5 and 8 were selected for construction of the summer uniforms.

\section{Selection of the design for the uniform}

Thirty designs were evaluated by a panel of judges under three different categories:-

1. Boys' summer uniform

2. Girls' summer uniform

3. Winter uniform for boys and girls

The responses were statistically analyzed. The results obtained are shown in following tables

Table 2 reveals that design no 7 obtained maximum marks i.e. 70 , hence was ranked at first position. Design no 5 got 68 marks and ranked second, followed by design no 4 at third position with a score of 63. Design no 6 and 10 were at fourth and fifth ranks with 60 and 55 marks respectively.

Designs with Sixth to tenth rank in descending order were as follows- Design 9 sixth rank, Design 8 seventh rank, Design 2 eighth rank, Design 1 ninth rank and Design 3 tenth rank. Design no. 7,5 and 4 were selected for the construction as they were at top three ranks.

It can be seen from Table 3 that design no 4 was at first position with a score of 82 . Design no 5 got 77 marks and ranked second while design no 3 was on third rank with 74 marks. Design no 1 and 6 were at fourth and fifth ranks with 67 and 54 marks respectively. Designs with sixth to tenth ranks in descending order were $10,2,8,9$ and 7 respectively.

Design no 4, 5, and 3 were the most preferred designs of shirts for boys and hence were selected for construction. 
The data in Table 4 depicts the ranks of the frocks for the girls. Design no 2 obtained maximum marks, i.e. 70 and was at first position. Design no 5 was at second rank with 67 marks. Design no 1 was third in order of preference with 61 marks. Design no 4 and 3 were at fourth and fifth ranks respectively. Sixth to tenth ranks in descending order were followed by $10,8,6,9$ and 7 respectively. Design no 2,5 and 1 were thus the most preferred designs of frocks and were selected for construction.

Table.1 Selection of the fabric for the uniforms

\begin{tabular}{|c|c|c|}
\hline SAMPLE NO & MARKS & RANK \\
\hline $\mathbf{1}$ & 65 & $4^{\text {TH }}$ \\
\hline $\mathbf{2}$ & 48 & $8^{\text {th }}$ \\
\hline $\mathbf{3}$ & 45 & $9^{\text {th }}$ \\
\hline $\mathbf{4}$ & 60 & $5^{\text {th }}$ \\
\hline $\mathbf{5}$ & 70 & $\mathbf{2}^{\text {nd }}$ \\
\hline $\mathbf{6}$ & 43 & $10^{\text {th }}$ \\
\hline $\mathbf{7}$ & 55 & $6^{\text {th }}$ \\
\hline $\mathbf{8}$ & 75 & $\mathbf{3}^{\text {rd }}$ \\
\hline $\mathbf{9}$ & 50 & $7^{\text {th }}$ \\
\hline $\mathbf{1 0}$ & 80 & $\mathbf{1}^{\text {st }}$ \\
\hline
\end{tabular}

Table.2 Evaluation of the designs of knickers for boys

\begin{tabular}{|c|c|c|}
\hline DESIGN NO & MARKS & RANK \\
\hline $\mathbf{1}$ & 45 & $9^{\text {TH }}$ \\
\hline $\mathbf{2}$ & 47 & $8^{\text {th }}$ \\
\hline $\mathbf{3}$ & 43 & $10^{\text {th }}$ \\
\hline $\mathbf{4}$ & 63 & $\mathbf{3}^{\text {rd }}$ \\
\hline $\mathbf{5}$ & 68 & $\mathbf{2}^{\text {nd }}$ \\
\hline $\mathbf{6}$ & 60 & $4^{\text {th }}$ \\
\hline $\mathbf{7}$ & 70 & $\mathbf{1}^{\text {st }}$ \\
\hline $\mathbf{8}$ & 51 & $7^{\text {th }}$ \\
\hline $\mathbf{9}$ & 52 & $6^{\text {th }}$ \\
\hline & 55 & $5^{\text {th }}$ \\
\hline
\end{tabular}

Table.3 Evaluation of the designs of shirt for boys

\begin{tabular}{|c|c|c|}
\hline DESIGN NO & MARKS & RANK \\
\hline $\mathbf{1}$ & 67 & $4^{\text {th }}$ \\
\hline $\mathbf{2}$ & 46 & $7^{\text {th }}$ \\
\hline $\mathbf{3}$ & 74 & $\mathbf{3}^{\text {rd }}$ \\
\hline $\mathbf{4}$ & 82 & $\mathbf{1}^{\text {st }}$ \\
\hline $\mathbf{5}$ & 77 & $\mathbf{2}^{\text {nd }}$ \\
\hline $\mathbf{6}$ & 54 & $5^{\text {th }}$ \\
\hline $\mathbf{7}$ & 33 & $10^{\text {th }}$ \\
\hline $\mathbf{8}$ & 36 & $8^{\text {th }}$ \\
\hline $\mathbf{9}$ & 35 & $9^{\text {th }}$ \\
\hline $\mathbf{1 0}$ & 48 & $6^{\text {th }}$ \\
\hline
\end{tabular}


Table.4 Evaluation of the designs of frock for girls

\begin{tabular}{|c|c|c|}
\hline DESIGN NO & MARKS & RANK \\
\hline $\mathbf{1}$ & 61 & $\mathbf{3}^{\text {rd }}$ \\
\hline $\mathbf{2}$ & 70 & $\mathbf{1}^{\text {st }}$ \\
\hline $\mathbf{3}$ & 58 & $5^{\text {th }}$ \\
\hline $\mathbf{4}$ & 60 & $4^{\text {th }}$ \\
\hline $\mathbf{5}$ & 67 & $\mathbf{2}^{\text {nd }}$ \\
\hline $\mathbf{6}$ & 48 & $8^{\text {th }}$ \\
\hline $\mathbf{7}$ & 39 & $10^{\text {th }}$ \\
\hline $\mathbf{8}$ & 51 & $7^{\text {th }}$ \\
\hline $\mathbf{9}$ & 45 & $9^{\text {th }}$ \\
\hline $\mathbf{1 0}$ & 55 & $6^{\text {th }}$ \\
\hline
\end{tabular}

Table.5 Evaluation of the designs of tracksuit for boys and girls for winter uniform

\begin{tabular}{|c|c|c|}
\hline DESIGN NO & MARKS & RANK \\
\hline $\mathbf{1}$ & 55 & $6^{\text {th }}$ \\
\hline $\mathbf{2}$ & 60 & $4^{\text {th }}$ \\
\hline $\mathbf{3}$ & 58 & $5^{\text {th }}$ \\
\hline $\mathbf{4}$ & 77 & $\mathbf{1}^{\text {st }}$ \\
\hline $\mathbf{5}$ & 67 & $\mathbf{2}^{\text {nd }}$ \\
\hline $\mathbf{6}$ & 65 & $\mathbf{3}^{\text {rd }}$ \\
\hline $\mathbf{7}$ & 48 & $9^{\text {th }}$ \\
\hline $\mathbf{8}$ & 51 & $8^{\text {th }}$ \\
\hline $\mathbf{9}$ & 45 & $10^{\text {th }}$ \\
\hline $\mathbf{1 0}$ & 53 & $7^{\text {th }}$ \\
\hline
\end{tabular}

Plate.1 Boys' summer uniform (knicker)
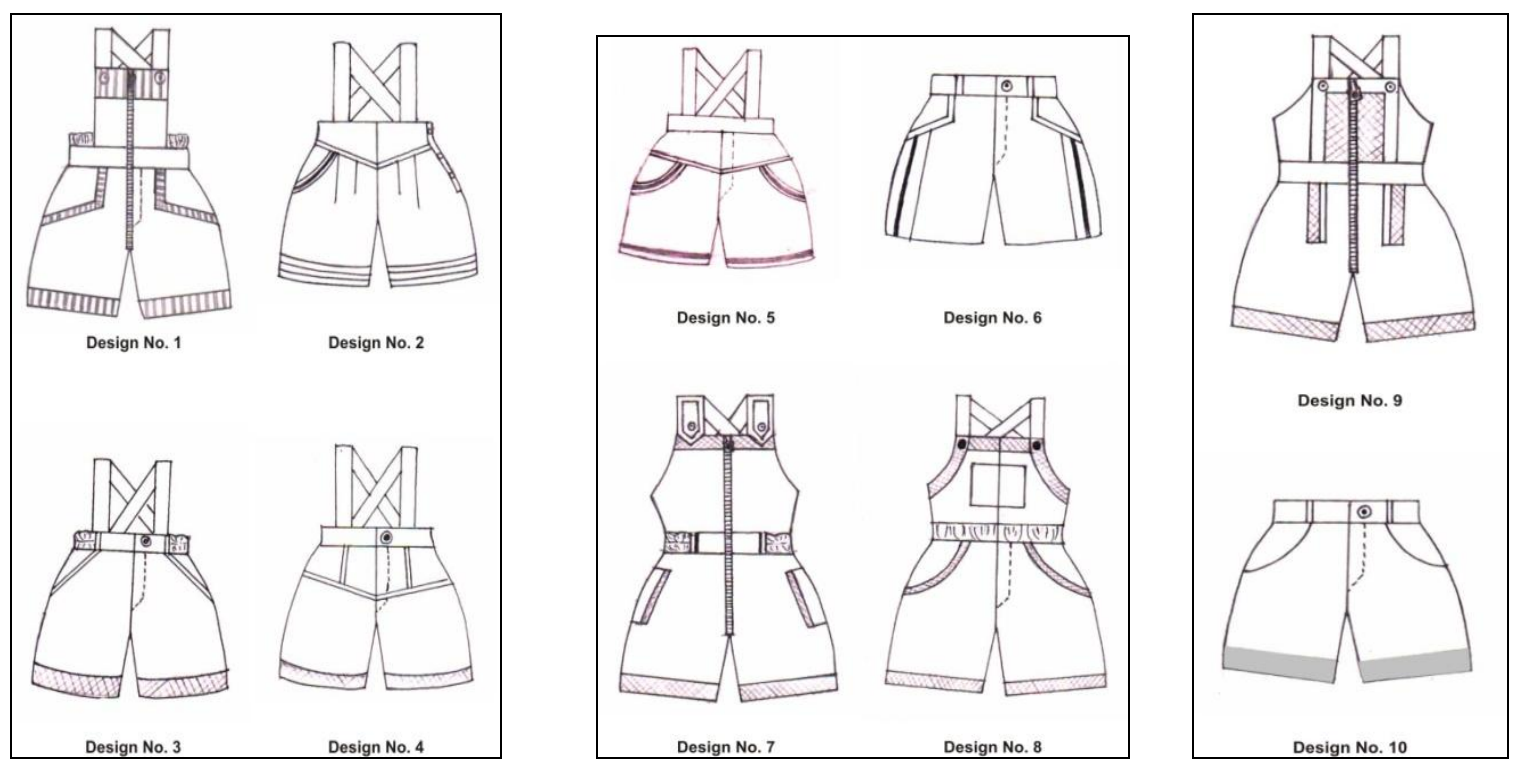
Plate.2 Boys' summer uniform (Shirt)
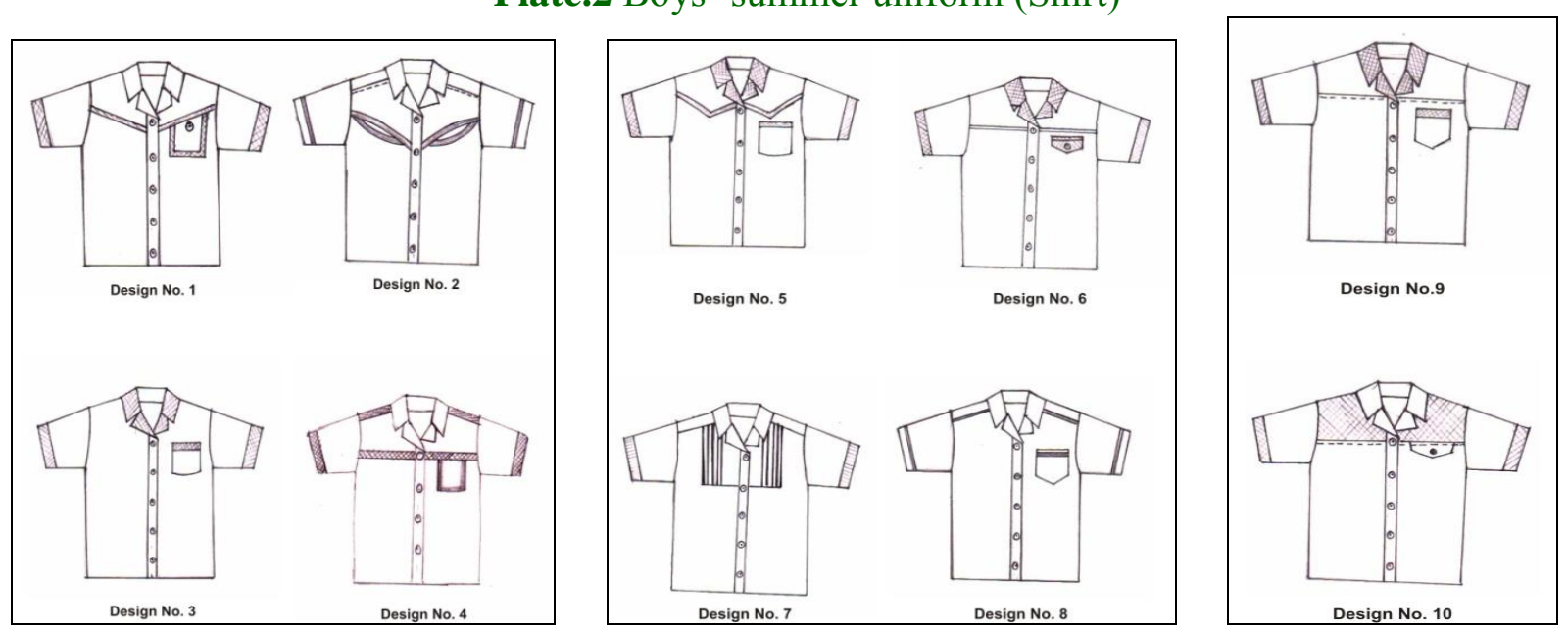

Plate.3 Girls' summer uniform
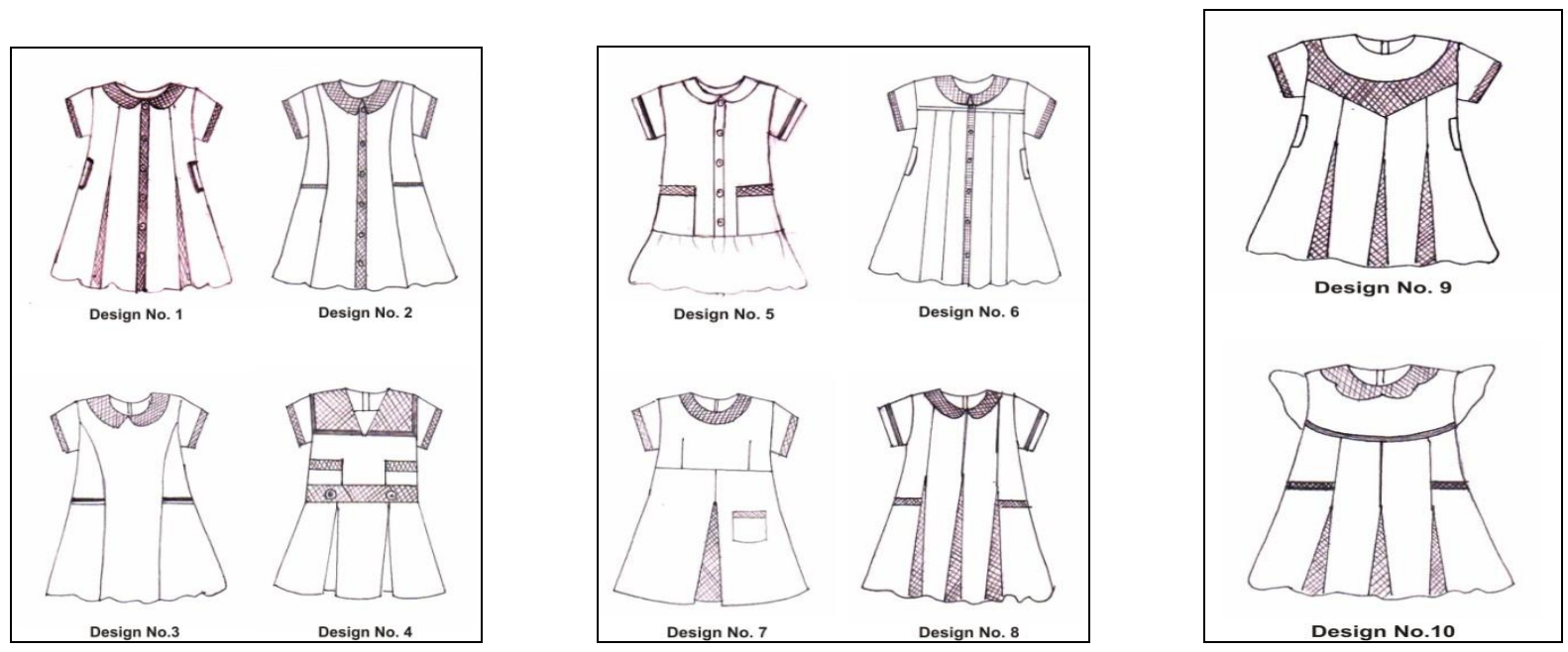

Plate.4 Winter uniform for boys and girls (tracksuits)
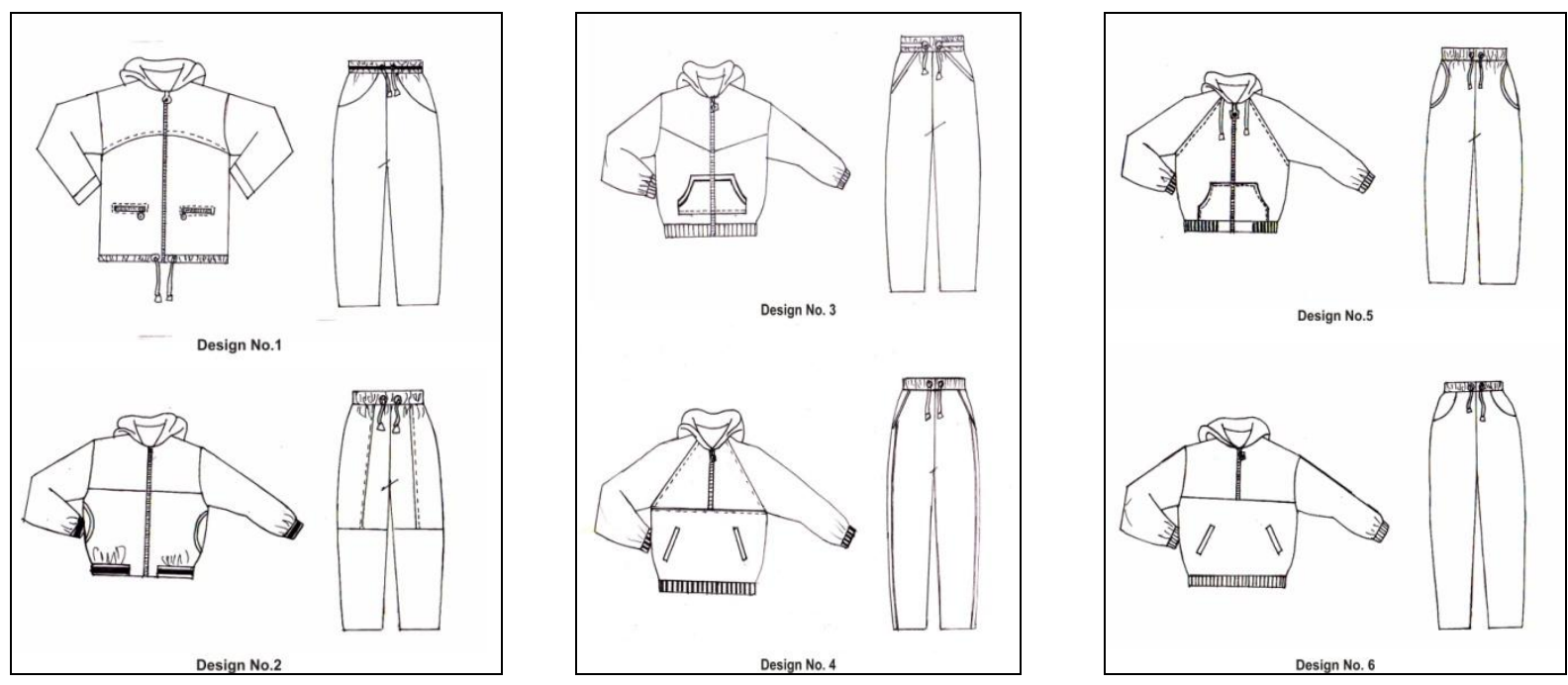
Plate.5 Winter uniform for boys and girls (tracksuits)
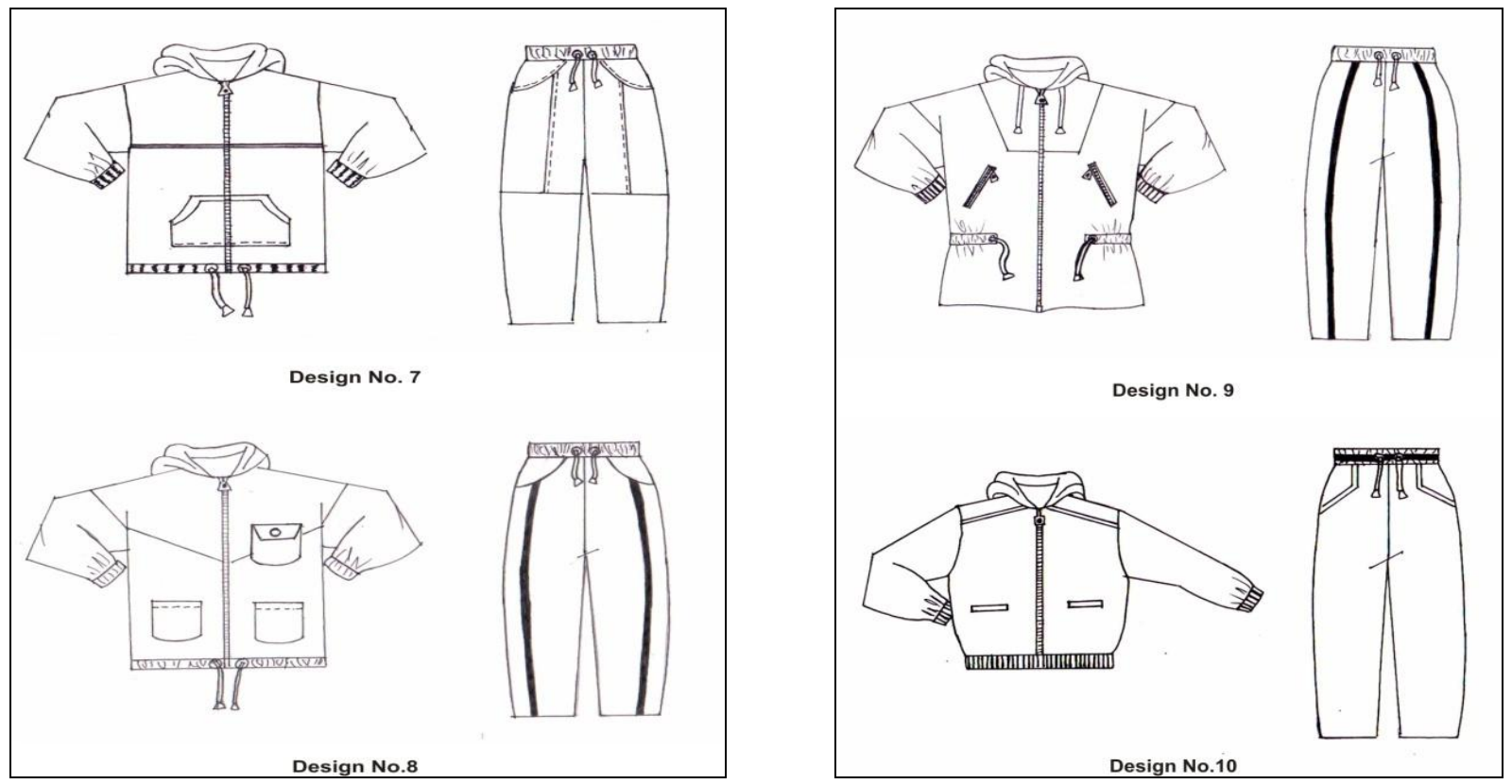

Constructed uniform rank no. 1

Plate.6 (A) Boy's Uniform and (B) Girl's Uniform

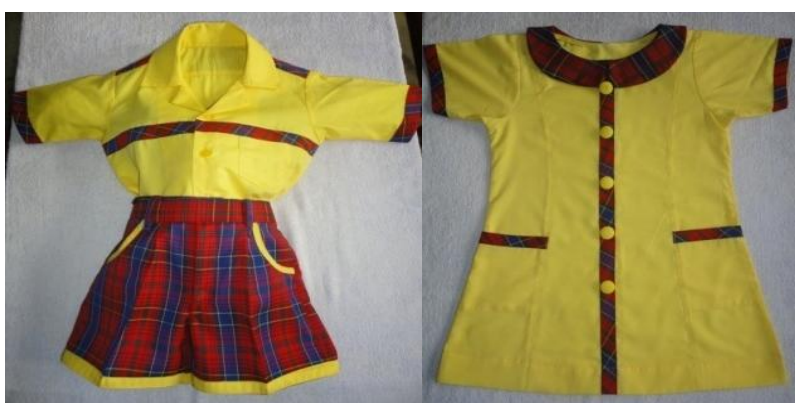

Constructed uniform rank no. 2

Plate.7 (C) Boy's Uniform and (D) Girl's Uniform

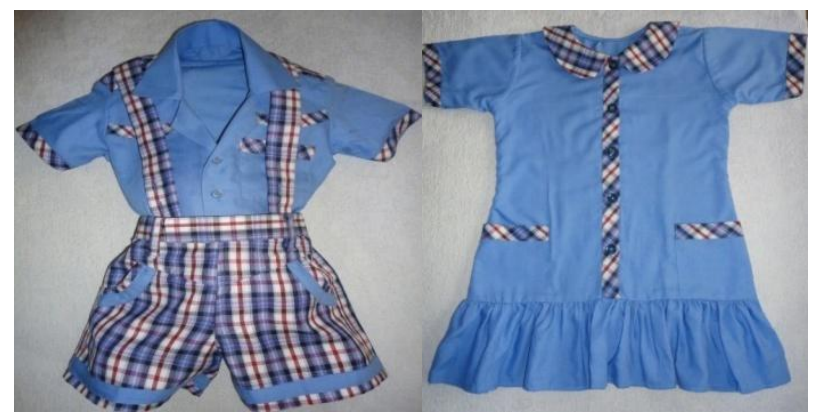


Constructed uniform rank no. 3

Plate.8 (E) Boy's Uniform and (F) Girl's Uniform

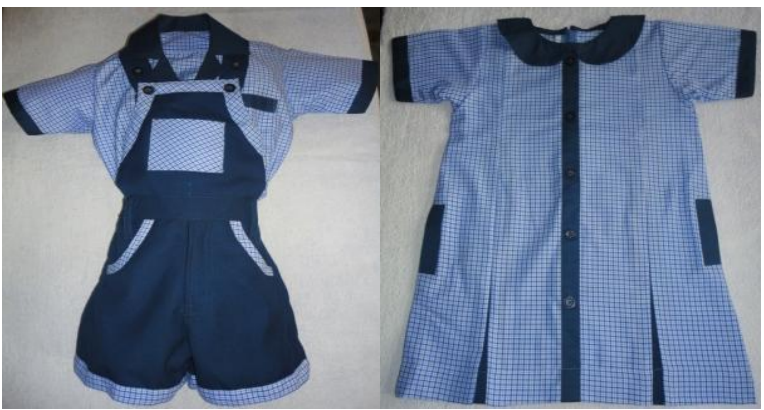

Table 5 shows that design no 4 secured highest marks, i.e. 77 and was ranked first. Design no 5 got 67 marks and ranked second, followed by design no 6 at third position with a score 65 . Design no 2 and 3 were at fourth and fifth ranks with 60 and 58 marks respectively. Sixth to tenth rank in descending order were design no $1,10,8,7$ and 9 respectively.

The constructed uniforms were then displayed in Chaitanya Laboratory Nursery School of the college and authorities showed an interest in replacing the present uniform by one of the designed uniforms.

In conclusion, pre-school age is of the most important part of an individual's life. At this stage of the life, the child is very active, so his clothes should be comfortable, protective, easy to wear and maintain. School uniforms are an important part of their clothing. School uniforms for pre-schoolers make the children identify themselves with the peer group as well as the school and give them a feeling of security and self- confidence. The uniforms for preschoolers need to be more comfortable in terms of style and material; and should have good colours combination of checks and plains in bright and light colours. They can be made more interesting by using combination of checks and plains, pockets and suitable collars. Accessories like ties, badges can be done away with. A comfortable and more appealing uniform can make a child more independent and confident thereby contributing towards child's self concept and better adjustment to new environment.

\section{References}

en.wikipedia.org/wiki/school-uniform

Gawne, EJ., and Oerke, BV, 1969, "Dress", The clothing textbook, Peoria Illinois Chas A, Bennett Co. Inc., USA, 286, 288, 290, 303.

Lewis and Dora, 1960, "Clothing Construction and Wardrobe", The Macmillan Company, New York, 200, 203.

Ryan, MS., 1966, "Clothing a study in Human behaviour", Holt, Richart and Winston INC, New York, Chicago, Sen Francesico Toronto, London, 204, 217.

\section{How to cite this article:}

Lalita Rani. 2020. Designing of the School Uniforms for Pre-School Children. Int.J.Curr.Microbiol.App.Sci. 9(02): 2689-2696. doi: https://doi.org/10.20546/ijcmas.2020.902.306 